\title{
FOOD AND HABITAT RELATIONSHIPS OF CLAASSENIA SABULOSA (PLECOPTERA: PERLIDAE) IN THE UPPER COLORADO RIVER, COLORADO
}

\author{
Richard A. Thorp ${ }^{1,2}$, Jeremy B. Monroe ${ }^{3}$, Emily C. Thorp ${ }^{4}$, \\ Todd Wellnitz ${ }^{5,6}$, and N. LeRoy Poff ${ }^{3}$
}

\begin{abstract}
Aвstract. - Streambed surveys were conducted along the upper Colorado River, Colorado, to describe the distributions of Claassenia sabulosa larvae in relation to current speed and to determine their diets. We also addressed diel feeding periodicity by sampling during both day and night. Claassenia sabulosa was more abundant in riffle habitats than in runs. A positive relationship existed between C. sabulosa abundance and stream current, with larval size increasing with current speed. Chironomidae, Baetidae, and Simulidae collectively accounted for $93 \%$ of the prey found in stonefly guts; however, these categories were not consumed equally by all C. sabulosa. Smaller C. sabulosa primarily ate chironomids, and larger individuals consumed more baetids. Only a slight difference existed in the percentage of empty guts between night- and day-collected stoneflies, and ranges of prey per gut at night were higher than those in the day, suggesting that these stoneflies may forage more intensively at night.
\end{abstract}

Key words: stoneflies, Claassenia sabulosa, Perlidae, current speed, ontogeny, predation, upper Colorado River.

Stoneflies of the family Perlidae are prominent members of stream macroinvertebrate communities of North America (Sheldon 1985). Although the ecological aspects of a few members of this important group are relatively well known, for many species this information is still lacking (DeWalt and Stewart 1995). To date, studies on perlid larval ecology have focused on 2 aspects: foraging behaviors and habitat relationships. These works describe perlid larvae as predominantly predators on a variety of invertebrate prey (Peckarsky and Penton 1985, Feminella and Stewart 1986, Allan et al. 1987, Allan and Flecker 1988, Fuller and Hynes 1987, Soluk 1990, Scrimgeour and Culp 1994, Duvall and Williams 2000, Stewart and Stark 2002) and have shown that their distributions across streambeds can be influenced by abiotic factors such as current velocity (Sheldon 1980, Feltmate et al. 1986) and substrate composition (Feltmate et al. 1986, Fuller and Rand 1990, Helešic 2001).

The stonefly Claassenia sabulosa (Claassen, 1931) is a relatively large invertebrate predator found in stream communities throughout the southern Rocky Mountains (Baumann et al. 1977, Alexander and Stewart 1996). Within these lotic habitats, larvae are commonly collected from streambed substrata of riffles (Richardson and Gaufin 1971). Chironomidae, Baetidae, and Simulidae are common prey for C. sabulosa (Richardson and Gaufin 1971, Allan 1982). The relative importance of each of these families varies both seasonally and with larval ontogeny (Fuller and Stewart 1977, 1979). Despite the trophic importance of these abundant stoneflies in western streams, few studies have identified their prey beyond the taxonomic level of order. Further, we know of no published reports relating the streambed distributions of C. sabulosa to microhabitat variables such as current speed.

In this study we examined a population of larval C. sabulosa within the upper Colorado River to address 3 questions. First, what prey do these predators consume and do ontogenetic feeding shifts occur? Second, do C. sabulosa larvae exhibit diel changes in foraging rates? And finally, are the benthic distributions of these animals related to current speed?

\footnotetext{
${ }^{1}$ Department of Bioagricultural Science and Pest Management, Colorado State University, Fort Collins, CO 80523.

2Present address: ENSR, 4303 LaPorte Avenue, Fort Collins, CO 80521. Email: rthorp@ensr.aecom.com

${ }^{3}$ Department of Biology and Graduate Degree Program in Ecology, Colorado State University, Fort Collins, CO 80523.

${ }^{4}$ Department of Clinical Sciences, Colorado State University, Fort Collins, CO 80523.

5 Department of Biology, Colorado State University, Fort Collins, CO 80523.

${ }^{6}$ Present address: Department of Biology, University of Wisconsin-Eau Claire, Eau Claire, WI 54702.
} 


\section{Study Area}

This study was conducted along a 50-m reach of the Upper Colorado River near Granby, Colorado, at an elevation of ca. 2420 $\mathrm{m}$ ASL. Streamflow along our study reach was regulated via a bottom-release dam located 7 $\mathrm{km}$ upstream at Lake Granby. Average streamflow for the study reach was $8 \mathrm{~m}^{3} \cdot \mathrm{s}^{-1}$, with peak discharge typically occurring during the month of June (1992-2001, USGS gaging station \#09034250). Our study reach was approximately $15 \mathrm{~m}$ wide and 50 meters long and consisted of a series of alternating run and riffle habitats. The streambed was composed of a matrix of large- to medium-sized cobbles and boulders over a layer of mixed gravels and sand. The canopy of our study reach was open, and the dominant riparian vegetation comprised various cottonwoods, willows, grasses, and forbs.

\section{METHODS}

To collect dietary and distributional data for C. sabulosa, we surveyed our study reach using 8 separate linear transects positioned perpendicular to the direction of streamflow. The length of each transect depended on stream width and ranged from 8 to $13 \mathrm{~m}$. To incorporate channel unit variability, both riffles and runs were studied. We distinguished between riffles and runs using depth and water surface characteristics; shallow areas with water surface turbulence were designated as riffle habitat, whereas runs were relatively deep and had little surface turbulence. Using these criteria, we arbitrarily selected a total of 4 riffles and 4 runs for study within our reach. From these 4 riffle and 4 run sections, we randomly selected 2 transects from each group to be sampled during the night and 2 to be sampled during the day. Night transect samples were collected between 0000 hours and 0300 hours using headlamps to aid vision. Day samples were collected between 1200 hours and 1500 hours. Both night and day survey data were collected on 8-10 August 2001.

Along each of the 8 transects described above, we sampled $1-\mathrm{m}^{2}$ plots at $1-\mathrm{m}$ intervals along the transect tape. We sampled 22 plots during the day and 23 plots at night. From the day riffle and run transects, 12 and 10 plots were sampled, respectively. The 4 night transects contained 12 riffle plots and 11 run plots.
To define the margins of each plot, we tied boundary ropes to rebar spaced $1 \mathrm{~m}$ apart and embedded within the streambed and the transect tape. Within each plot we measured current speed at $60 \%$ of the water column depth using an average of 5 equally spaced points with a Schiltknecht MiniWater 2 microprobe probe (8-mm-diameter propeller, 7-sec reading). After current speed was measured, we disturbed the streambed within each plot by kicking for 1 minute. Dislodged invertebrates were captured in a 1.5-m-wide $\times 1$-m-tall, 500$\mu \mathrm{m}$-mesh kickseine at the downstream side of each plot. All macroinvertebrates and associated debris were quickly removed from the kickseine surface with a paintbrush or by hand and immediately preserved in a $10 \%$ formalin solution for sorting and processing at a later time.

All C. sabulosa interocular distances were measured to the nearest $0.1 \mathrm{~mm}$ using a dissecting microscope equipped with an optical stage micrometer. After measurement the foregut of each larva was removed using methods described in Hynes (1941) and in Richardson and Gaufin (1971), and the prey items within each were identified to the family level.

\section{Data Analysis}

We plotted C. sabulosa abundance and head capsule width separately against the mean current speed collected from each transect plot. Abundances of C. sabulosa in riffle versus run habitats, numbers of prey items found in larval guts in the day versus the night, and numbers of C. sabulosa larvae collected during the day versus night were each compared using Wilcoxon Rank Sum Tests because these data failed to meet the statistical assumptions of normality (SAS Institute, Inc. 2001).

\section{Results}

From the 45 plots sampled along the 8 transects, 135 C. sabulosa larvae were collected and 220 prey items were dissected from their guts (Table 1). Of these prey items, insects from the families Baetidae, Chironomidae, and Simulidae collectively accounted for $93 \%$ of the total identified prey. The remaining $7 \%$ was composed of individuals from Hydropsychidae, Lepidostomatidae, Limnephilidae, Perlidae, Heptageniidae, and Ephemerellidae, and pupae of Trichoptera. 
TABLE 1. Taxonomic groupings and numerical values by total and percent of total prey items $(n=220)$ found in Claassenia sabulosa guts.

\begin{tabular}{lcc}
\hline Taxonomic group & $\begin{array}{c}\text { Total } \\
\text { in guts }\end{array}$ & $\begin{array}{c}\text { Percent } \\
\text { of total }\end{array}$ \\
\hline $\begin{array}{l}\text { EPHEMEROPTERA } \\
\text { Baetidae }\end{array}$ & 80 & 36 \\
$\quad$ Ephemerellidae & 1 & $<1$ \\
$\quad$ Heptageniidae & 1 & $<1$ \\
PLECOPTERA & & \\
$\quad$ Perlidae & 2 & 1 \\
TrichopTERA & & \\
$\quad$ Hydropsychidae & 3 & $<1$ \\
$\quad$ Lepidostomatidae & 1 & $<1$ \\
Limnephilidae & 1 & 2 \\
$\quad$ Unidentified pupa & 4 & 36 \\
DiPTERA & & 21 \\
$\quad$ Chironomidae & 80 & \\
Simulidae & 47 & \\
\hline
\end{tabular}

Common food items were not consistent across the different sizes of $C$. sabulosa larvae. Chironomidae were frequently dissected from the guts of smaller C. sabulosa, but showed no trend $(r=-0.11, P=0.5)$ of changing importance in the diets of individuals across a range of body sizes (Fig. 1). Conversely the number of baetid mayflies consumed by C. sabulosa larvae showed a significant $(r=0.49, P=$ $0.001)$ positive association with $C$. sabulosa head capsule width (Fig. 1). We collected a total of 88 C. sabulosa from day plots, compared to only 47 at night; and the median number of C. sabulosa larvae collected from day plots $\left(3.5\right.$ larvae $\left.\cdot \mathrm{m}^{-2}\right)$ was significantly greater than the number collected from night plots (2 larvae $\cdot \mathrm{m}^{-2} ; P=0.03$; Fig. 2 ). The median number of prey items in the guts of $C$. sabulosa from our night samples was the same as for the day samples, but ranges differed considerably (Table 2). In all, $45 \%$ of C. sabulosa larvae collected from day transect plots had empty guts, while $43 \%$ of stoneflies from night samples were empty.

The average current speed based on 5 measurements within our study plots ranged from 0.03 to $0.79 \mathrm{~m} \cdot \mathrm{s}^{-1}$. Current speed within riffle plots $\left(\bar{x}=0.46 \mathrm{~m} \cdot \mathrm{s}^{-1}, s_{\bar{x}}=0.22 \mathrm{~m} \cdot \mathrm{s}^{-1}\right)$ was almost twice that measured in run plots $\left(\bar{x}=0.27 \mathrm{~m} \cdot \mathrm{s}^{-1}, s_{\bar{x}}=0.13 \mathrm{~m} \cdot \mathrm{s}^{-1}\right)$, and the average abundance of $C$. sabulosa larvae was greater in riffle plots $(P=0.001$; Table 3$)$. Irrespective of larval size, C. sabulosa showed

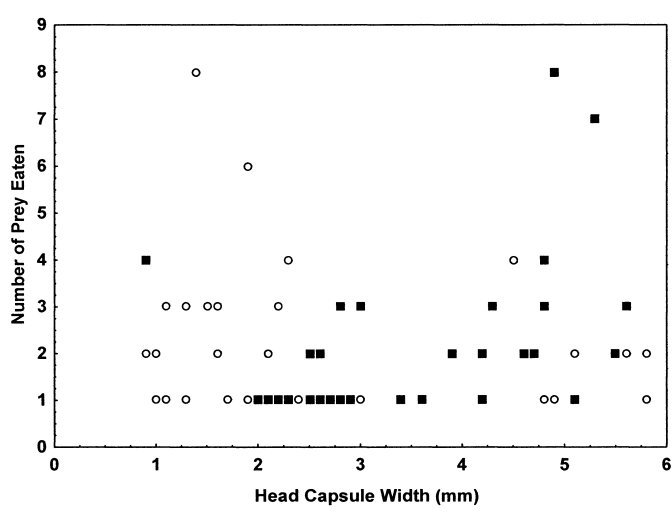

Fig. 1. Number of chironomids (open circles, $r=-0.11$, $P=0.5)$ and baetids (closed squares, $r=0.49, P=0.001$ ) eaten by Claassenia sabulosa $(n=80$ stoneflies) of various head capsule widths. Stoneflies with empty guts were excluded from these analyses.

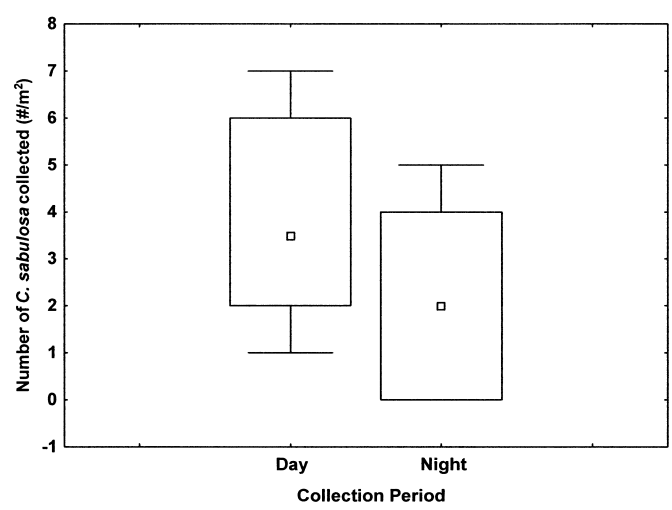

Fig. 2. Comparison of the median number of Claassenia sabulosa captured per survey plot in day (3.5 C. sabulosa per plot, $n=22$ plots) versus night ( 2 C. sabulosa per plot, $n=23$ plots) collection periods using a Wilcoxon rank sum test $(P=0.03)$. Squares represent group medians, boxes represent $25 \%-75 \%$ ranges, and whiskers represent $10 \%-90 \%$ ranges.

a positive relationship with the average current speed of study plots $(r=0.30, P=0.04$; Fig. 3). An even stronger positive relationship existed between $C$. sabulosa head capsule and current speed ( $r=0.25, P=0.003$; Fig. 4).

\section{DisCUSSION}

Our diet analyses closely parallel the findings of Fuller and Stewart (1977), who found 
TABle 2. Percentage of empty guts, median number of prey items per Claassenia sabulosa gut, and associated ranges from night $(n=47)$ versus day plots $(n=88)$.

\begin{tabular}{lccc}
\hline Habitat & $\begin{array}{c}\text { Empty } \\
\text { guts }\end{array}$ & $\begin{array}{c}\text { Prey items } \\
\text { per stonefly }\end{array}$ & Range \\
\hline Night plots & $43 \%$ & 1 & 28 \\
Day plots & $45 \%$ & 1 & 10 \\
\hline
\end{tabular}

TABLE 3. Abundance of Claassenia sabulosa collected from riffle $(n=24)$ and run $(n=21)$ plots, including mean current speeds. Abundances of C. sabulosa in riffles and runs $(P=0.001)$ were compared with a Wilcoxon rank sum test. The median number of stoneflies collected from plots in riffles and runs are listed with associated standard deviations.

\begin{tabular}{lccc}
\hline Habitat & $\begin{array}{r}\text { Mean current } \\
\text { speed }\left(\mathrm{m} \cdot \mathrm{s}^{-1}\right)\end{array}$ & $\begin{array}{c}\text { C. sabulosa } \\
\text { per } \mathrm{m}^{2}\end{array}$ & $s$ \\
\hline Riffle plots & 0.46 & 4 & 3.1 \\
Run plots & 0.27 & 2 & 1.7 \\
\hline
\end{tabular}

that in the Gunnison River, Colorado, during August, both small (head capsule width $<2.5$ $\mathrm{mm}$ ) and large (head capsule width $>2.5 \mathrm{~mm}$ ) C. sabulosa fed mostly on chironomids. However, in a similar study from the Dolores River, Colorado, Fuller and Stewart (1979) found that both small and large C. sabulosa fed mainly on various mayflies during August. These investigators suggested that the discrepancies in the diets of these 2 stonefly populations were likely due to a difference in the available prey in each river.

To our knowledge, this study represents the 1st report of pupal and case-making Trichoptera in guts of the stonefly C. sabulosa. Although occurrence of such prey in our samples was rare, it is nevertheless novel and notable. We did not find any associated case fragments with larval remains, and these prey were completely intact, which may indicate that these prey were first pulled from their protective cases before being engulfed. The occurrence of sessile trichopteran pupae in C. sabulosa guts should be expected, since perlids are very mobile predators (Feltmate and Williams, 1991) and would be predicted to encounter sessile prey more often than mobile prey (Taylor et al. 1978). Also notable, the perlid stoneflies that we dissected from guts were positively identified as C. sabulosa and represent the 1st pub-

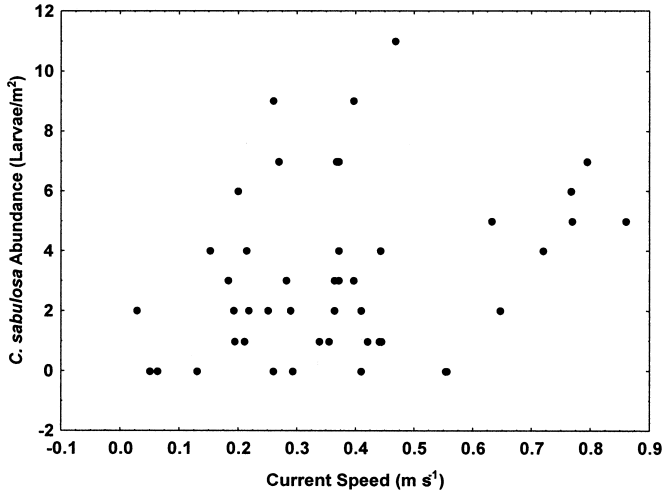

Fig. 3. Abundance of Claassenia sabulosa $(n=135)$ larvae compared to average current speeds for 45 survey plots $(r=0.30, P=0.04)$.

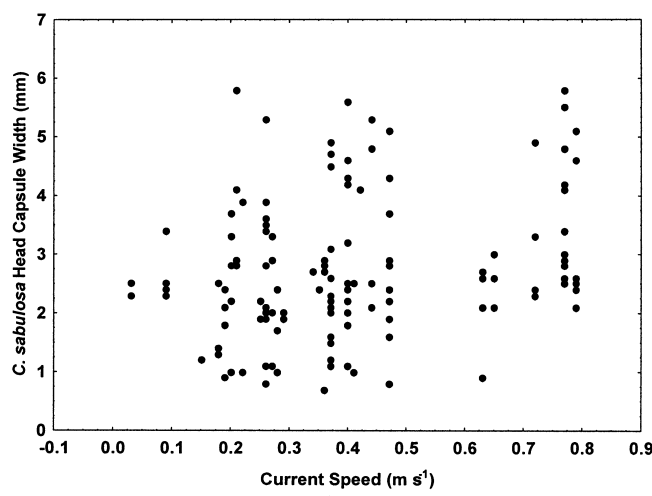

Fig. 4. Head capsule width of Claassenia sabulosa larvae $(n=135)$ compared to average current speeds for 45 survey plots $(r=0.25, P=0.003)$.

lished report of cannibalism in this stonefly species.

We found little difference between the percent of empty C. sabulosa guts in day versus night plots, and the median number of prey in stoneflies was identical. The ranges of prey eaten during the 2 periods differed greatly, which suggests that some individuals may have foraged more intensively at night as suggested by Johnson (1983) for the western perlid Hesperoperla pacifica in an Idaho River and Johnson (1981) for 3 eastern perlids in a New York stream. Because our effectiveness in sampling at night was probably reduced by our limited ability to visually locate and capture all $C$. 
sabulosa that were seined, we may have underestimated the extent of nocturnal feeding by this stonefly.

Within our study reach, current speed was weakly positively correlated with C. sabulosa abundance, and the size of C. sabulosa larvae increased with current speed. A plausible explanation for these observations is that habitats with fast and slow current speeds are partitioned between the different sizes of larvae and that an ontogenetic shift in habitat use may occur in this species. The prey differences that exist across current speeds would presumably contribute to such a shift in habitat use, as might different densities of fish predators. Indeed, Baetis mayflies are also positively correlated with current speed in this system (Monroe 2002), and brown trout are found primarily in slower-moving runs. Although this stonefly has been previously described as abundant in riffle areas (Richardson and Gaufin 1971, Fuller and Stewart 1977), no previous published studies document the relation of abundance to current speed.

\section{ACKNOWLEDGMENTS}

We thank Dr. Boris Kondratieff for reviewing this manuscript. We also thank the Tillotson and Mirr families for their patience and graciousness while providing access to our study reach. We thank the National Science Foundation's Research Experience for Undergraduates (REU) program and NSF DEB grant 0075352 to NLP and TW for providing funding for this research.

\section{Literature Cited}

Alexander, K.D., AND K.W. SteWaRT. 1996. Descriptions and theoretical considerations of mate finding and other adult behaviors in a Colorado population of Claassenia sabulosa (Plecoptera: Perlidae). Annals of the Entomological Society of America 89:290-296.

ALLAN, J.D. 1982. Feeding habits and prey consumption of three setipalpian stoneflies (Plecoptera) in a mountain stream. Ecology 63:26-34.

Allan, J.D., And A.S. Flecker. 1988. Prey preference in stoneflies: a comparative analysis of prey vulnerability. Oecologia 76:496-503.

Allan, J.D., A.S. Flecker, And N.L. MCClintock. 1987. Prey preference of stoneflies: sedentary versus mobile prey. Oikos 49:323-331.

Baumann, R.W., A.R. Gaufin, and R.F. Surdick. 1977. The stoneflies (Plecoptera) of the Rocky Mountains. Memoirs of the American Entomological Society 31.
DeWalt, R.E., AND K.W. SteWART. 1995. Life histories of stoneflies (Plecoptera) in the Rio Conejos of southern Colorado. Great Basin Naturalist 55:1-18.

Duvall, C.J., and D.D. Williams. 2000. Ontogenetic changes in prey consumption by the stonefly Paragnetina media in relation to temporal variation in prey nutrient content. Canadian Journal of Zoology 78: 748-763.

Feltmate, B.W., R.L. Baker, and P.J. Pointing. 1986. Distribution of the stonefly nymph Paragnetina media (Plecoptera: Perlidae) influence of prey, predators, current speed, and substrate composition. Canadian Journal of Aquatic Science 43:1582-1587.

Feltmate, B.W., AND D.D. Williams. 1991. Path and spatial learning in a stonefly nymph. Oikos 60:64-68.

Feminella, J.W., and K.W. SteWart. 1986. Diet and predation by three leaf-associated stoneflies (Plecoptera) in an Arkansas mountain stream. Freshwater Biology 16:521-538.

FulleR, R.L., AND H.B.N. Hynes. 1987. Feeding ecology of three predacious aquatic insects and two fish in a riffle of the Speed River, Ontario. Hydrobiologia 150: 243-255.

FUlLER, R.L., AND P.S. RAND. 1990. Influence of substrate type on vulnerability of prey to predacious aquatic insects. Journal of the North American Benthological Society 9:1-8.

Fuller, R.L., AND K.W. Stewart. 1977. The food habits of stoneflies (Plecoptera) in the upper Gunnison River, Colorado. Environmental Entomology 6:293-302.

1979. Stonefly (Plecoptera) food habits and prey preference in the Dolores River, Colorado. American Midland Naturalist 101:170-181.

HeLEŠIC, J. 2001. Nonparametric evaluation of environmental parameters determining the occurrence of stonefly larvae (Plecoptera) in streams. Aquatic Sciences 63:490-501.

Hynes, H.B.N. 1941. The taxonomy and ecology of the nymphs of British Plecoptera with notes on adults and eggs. Transactions of the Royal Entomological Society, London 91:10.

Johnson, J.H. 1981. Food habits and dietary overlap of perlid stoneflies (Plecoptera) in a tributary of Lake Ontario. Canadian Journal of Zoology 59:2030-2037. . 1983. Diel food habits of two species of setipalpian stoneflies (Plecoptera) in tributaries of the Clearwater River, Idaho. Freshwater Biology 13:105-111.

Monroe, J.B. 2002. Scales and sources of habitat structure shaping grazer distributions in the upper Colorado River. Master's thesis, Colorado State University, Fort Collins.

Peckarsky, B.L., And M.A. Penton. 1985. Is predacious stonefly behavior affected by competition? Ecology 66:1718-1728.

Richardson, J.W., AND A.R. Gaufin. 1971. Food habits of some western stonefly nymphs. Transactions of the American Entomological Society 97:91-121.

SAS Institute, InC. 2001. SAS, version 8.2. Cary, NC.

SCRImgeour, G.J., AND J.M. CulP. 1994. Foraging and evading predators: the effect of predator species on a behavioral trade-off by a lotic mayfly. Oikos 69:71-79.

Sheldon, A.L. 1980. Resource division by perlid stoneflies (Plecoptera) in a lake outlet ecosystem. Hydrobiologia 71:155-161. 
1985. Perlid stoneflies (Plecoptera) in an Appalachian drainage: a multivariate approach to mapping stream communities. American Midland Naturalist 113:334-342.

Soluk, D.A. 1990. Postmolt susceptibility of Ephemerella larvae to predatory stoneflies: constraints on defensive armour. Oikos 58:336-342.

Stewart, K.W., and B.P. Stark. 2002. Nymphs of North American stonefly genera (Plecoptera). Caddis Press, Columbus, $\mathrm{OH}$.
TAYLOR, L.R., I.P. Woiwod, And J.N. Perry. 1978. The density dependence of spatial behaviour and the rarity of randomness. Journal of Animal Ecology 47: 383-406.

Received 1 February 2006 Accepted 29 July 2006 